\title{
An experimental evaluation of the greenhouse effect in the substitution of R134a with pure and mixed HFO in a domestic refrigerator
}

\author{
Ciro Aprea ${ }^{1}$, Adriana Greco $^{2 *}$, Angelo Maiorino ${ }^{1}$ \\ ${ }^{1}$ DIIN, University of Salerno, Via Giovanni Paolo II 132, Fisciano (SA) 84084, Italy \\ ${ }^{2}$ DII, University of Naples “Federico II”, P. le Tecchio 80, Napoli 80125, Italy
}

Email: adriana.greco@unina.it

\begin{abstract}
Due to the UE Regulation n. 517/2014 refrigerants with a GWP higher than 150 are not allowed from January 1, 2015 in new domestic refrigerators. Thus, a replacement for HFC134a is needed.

In this paper attention is devoted to the evaluation of the environmental impact in terms of greenhouse effect of the substitution of HFC134a with low GWP, HFO refrigerant fluids. The greenhouse effect is accounted for by the experimental evaluation of the TEWI index (Total Equivalent Warming Impact) that takes into account both direct and indirect contributions to global warming. The refrigerant fluids that have been tested as a drop-in are: pure HFO1234yf, the mixture HFO1234yf/HFC134a (90/10\% in weight), pure HFO1234ze, the mixture HFO1234ze/HFC134a (90/10 \% in weight). In particular, with the mixture HFC134a/HFO1234yf (10/90 \% in weight) there is a reduction of the TEWI of $-295 \%$ respect to HFC134a.
\end{abstract}

Keywords: HFC134a, HFO1234yf, HFO1234ze, Experimental Plant, Greenhouse Effect, TEWI.

\section{INTRODUCTION}

About $17 \%$ of the worldwide energy consumption originates from refrigeration. Most modern refrigeration units are based on vapour compression plants. Since the very beginning of their commercial diffusion, the development of the latter is strictly related to the characteristics of working fluids. The traditional refrigerant fluids, i.e. CFCs and HCFCs, have been banned by the Montreal Protocol [1] because of their contribution to the disruption of the stratospheric ozone layer (Ozone-Depleting substances ODs).

Human activities have increased the concentration of greenhouse gases in the atmosphere. This resulted in a substantial warming of earth surface and atmosphere that adversely affected the natural ecosystem [2]. The impact that greenhouse gases on global warming is quantified by their GWP (Global Warming Potential). The GWP is defined as the mass of $\mathrm{CO}_{2}$ that would result in the same net impact on global warming as the release of a single unit $(\mathrm{kg})$ of the atmospheric component in question.

The Kyoto Protocol [3], pursuant to the United Nations Framework Convention on Climate Change (UNFCCC), sets binding targets for greenhouse gas emissions.

National laws and regulations implementing the Kyoto Protocol differ from one another, but they typically prohibit avoidable releases of HFC and PFC refrigerants.

In the field of domestic refrigeration, based on the UE Regulation $\mathrm{N}^{\circ} 517 / 2014$, HFCs with 150 or more as GWP has been forbidden from 1 January 2015.

Domestic refrigeration is one of the most energyconsumption home appliances. Because of its thermodynamics and thermo-physical properties, one of the most utilized refrigerant is HFC134a until the Kyoto protocol established its phasing out due to its too high GWP (1430) [4].

The above-mentioned restrictions are forcing the shift to a fourth generation of refrigerants with both ODP and GWP regulations. In this new generation of refrigerants there are HydroFluoroOlefins (HFOs) that are derived from olefins rather than alkanes. Two well-known and promising HFOs are: HFO1234yf and HFO1234ze. Such refrigerants present zero ODP and very small GWPs which ensures a very brief duration once dispersed in the atmosphere. The nowadays state of the art reveals that HFOs have been tested as drop-in replacement of domestic refrigerators already working with HFO134a.

A Vapor Compression Plant (VCP) generates typically both a direct and an indirect contribution to global warming, where the first one is related to the GWP of the fraction of refrigerant charge released accidentally in the atmosphere or not recovered when the system is scrapped. The indirect contribution consists in the so-called energy-related contribution, which originates from $\mathrm{CO}_{2}$ emissions in the atmosphere due to the energy production processes. Hence, the employment of refrigerants with low direct impact doesn't guarantee consequentially a low indirect impact in the VCP. TEWI (Total Equivalent Warming Impact), is one of the most comprehensive parameter which takes in account both indirect and direct contribution to global warming of a refrigerant fluid. 
In this paper are reported the results of an experimental comparative analysis between: HFC134a, pure HFO1234ze, HFO1234ze/HFC134a (90/10 \% by weight) mixture, pure HFO1234yf, HFO1234yf/HFC134a (90/10 \% by weight) mixture in terms of TEWI. All the tests have been conducted under subtropical conditions, and the energy consumptions have been measured in accordance with the normative UNIEN-ISO15502 [5].

\section{THE TEWI CONCEPT}

The concept of total equivalent warming impact (TEWI) was developed to combine the effect of direct refrigerant emission with those due to energy consumption and the related combustion of fossil fuels for the electric energy production. TEWI provides a measure of the environmental impact of greenhouse gases originating from operation, service and endof-life disposal of the equipment. TEWI is the sum of the direct contribution of the greenhouse gases used to make or operate the systems and the indirect contribution of carbon dioxide emissions resulting from the energy required to run the systems over their normal lifetimes [6-14]. The TEWI is calculated as:

$$
\begin{aligned}
& \mathrm{TEWI}=\mathrm{CO}_{2, \mathrm{dir}}+\mathrm{CO}_{2, \text { indir }} \\
& \mathrm{CO}_{2, \text { dir }}=\mathrm{RC}\left[\mathrm{p}_{\mathrm{L}}+\left(\frac{1-\mathrm{REC}}{\mathrm{V} \prime}\right)\right] \mathrm{V}^{\prime} \cdot \mathrm{GWP} \\
& \mathrm{CO}_{2, \text { indir }}=\alpha \cdot \frac{\mathrm{Q}_{\mathrm{ref}}^{\prime}}{\mathrm{COP}} \cdot \mathrm{H} \cdot \mathrm{V}^{\prime}
\end{aligned}
$$

The direct global warming effect of refrigerant fluids, stemming from the absorption they produce of long-wave radiations, depends on their GWP and on the fraction of refrigerant charge released in the atmosphere. The last is mainly due to leakages $(0.5 \%)$ during the operational plant life time (15 years).

As already stated, the indirect contribution to TEWI consists in the so-called energy-related contribution. Indeed, an electrical refrigerator requires electrical energy from a $\mathrm{CO}_{2}$ releasing power plant that typically burns a fossil fuel. The amount of $\mathrm{CO}_{2}$ emitted is a function of the refrigerator COP, of the power plant efficiency and of the fuel used in the conversion plant that affect the emissions per unit energy converted. The typical power-plant technology adopted varies from one country to another. The literature provides some indicative, average levels of $\mathrm{CO}_{2}$ release per $\mathrm{KWh}$ of electrical energy for various countries (r). For Italy, the value is 0.4109 $\mathrm{kg} \mathrm{CO} / \mathrm{kWh}_{\mathrm{e}}$

\section{EXPERIMENTAL EQUIPMENTS}

The schematic of the experimental setup of the single evaporator HCF134a domestic refrigerator (with a total volume of 473 l) is reported in Figure 1 [15].

The experimental apparatus is composed by: a hermetic reciprocating compressor, a forced air cooled condenser, a capillary tube and an evaporator operating in forced convection. The evaporator is placed in the freezer and an air distribution system connects the refrigerator to the freezer. A damper valve, moved using a thermostatic mechanical drive, controls the amount of air delivered to the refrigerator compartment. The capillary tube is wrapped for a good portion of its length $(>90 \%)$ around the suction tube of the compressor.

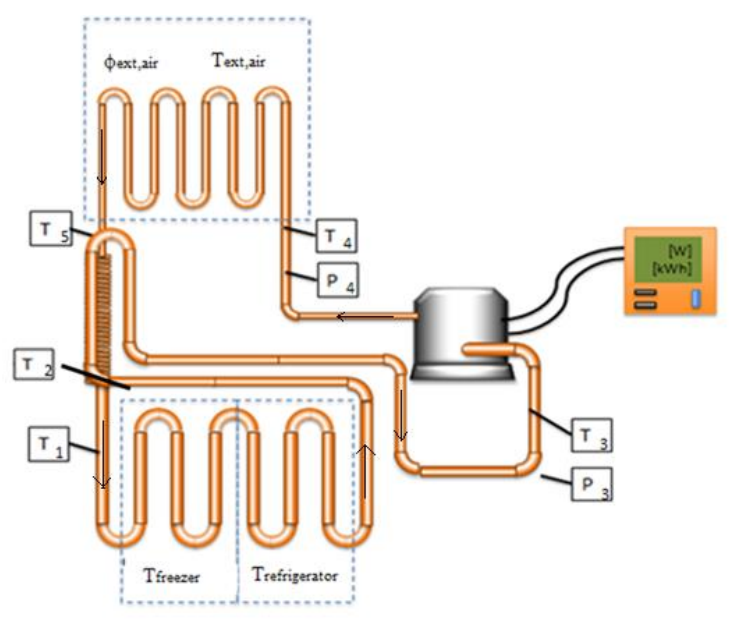

Figure 1. A schematic of the experimental plant

The scheme is fitted with an adaptive defrost control system that lies in electric resistors arranged in the proximity of the evaporator.

The insulation of the entire pipes of the plant is ensured using a $25-\mathrm{mm}$ thick flexible tube.

The location of all the sensors of the experimental plant is shown in Fig 1. Temperature measurements have been carried out by seven PT100 thermo-resistances (accuracy $\pm 0.15 \mathrm{~K}$ ) placed in the circuit. Pressure measurements have been carried out using two piezoelectric absolute pressure gauge (accuracy $\pm 0.2 \%$ ) placed at the inlet and the outlet of the compressor. An energy meter measured both the electric energy and the electric power absorbed by the refrigerator during the tests (accuracy $\pm 1 \%$ ). A thermo-hygrometer monitored the temperature and relative humidity of the air in the room test (accuracy $\pm 0.15^{\circ} \mathrm{C}, \pm 1 \%$ ). To evaluate the refrigerant charge of the plant, an electronic balance was used with an accuracy of $\pm 0.1 \mathrm{~g}$. According to Moffat [16] the uncertainty on the mixture mass fraction is $\pm 1 \%$.

Each sensor was connected to a 32-bit A/D acquisition system attached to a personal computer that allows a sample rate up to $10 \mathrm{kHz}$. Frigocheck 2.0, a virtual instrument developed in Labview area, has been utilized for real-time monitoring of pressure and temperature evolutions in the whole domestic experimental apparatus. With the measured, steady state values of pressure and temperature along the circuit, it is possible to evaluate the refrigerant enthalpy using the computer program RefProp 9.1. For different operating conditions, it was estimated for the enthalpy an accuracy within the range: $\pm 1.10-1.95 \%$.

In this paper the experimental facility, a domestic refrigerator that belongs to the A+ class for energy efficiency, has been equipped to make a comparison between HFC134a and the drop-in substitutes: pure HFO1234ze, pure HFO1234yf, the mixture HFC134a/HFO1234ze (10/90\% weight) and the mixture HFC134a/HFO1234yf (10/90\% weight). Drop-in experiments have been carried out without any modifications of the set-up.

All the experimental tests have been conducted according to the UNI-EN-ISO15502. The standard requires 24-hour tests while the refrigerator is in an environment which presents 
$25^{\circ} \mathrm{C}$ as average temperature and a relative humidity confined in the $45 \div 75 \%$ range.

The freezer set-point has been set to $-18^{\circ} \mathrm{C}$. The refrigerator thermostat has been adjusted to maintain the temperature at + $5{ }^{\circ} \mathrm{C}$. To operate in accordance with the above standard, it is also necessary that during the 24-hour tests, the refrigerator experiences at least one defrost cycle.

As per manufacturer's recommendation, $100 \mathrm{~g}$ of $\mathrm{HFC} 134 \mathrm{a}$ has been charged in the experimental plant for conducting baseline tests. Then, the refrigerator was charged with pure HFO1234ze and pure HFO1234yf and the optimal charge has been identified (136 and $115 \mathrm{~g}$, respectively). GWPs of HFO1234ze and HFO1234yf are 6 and 4, respectively. Whereas GWP of HFC134a is 1430. Experimental tests have been performed also with HFO1234ze/HFC134a and HFO1234yf/HFC134a mixtures. It is possible to add $10 \%$ of HFC134a to pure HFO and the mixture has a GWP lower than 150. The plant was charged with both HFO1234yf/HFC134a and HFO1234yf/HFC134a mixtures (90/10\% by weight) and the optimal charge of 116 and 137, respectively, was determined.

The experimental tests that have been conducted in order to evaluate the experimental value of the TEWI are $24 \mathrm{~h}$ tests. In these tests, the energy consumption in a $24 \mathrm{~h}$ test for each refrigerant fluid have been carried out to characterize the actual operating conditions of the domestic refrigerator. To operate in accordance with the UNI-EN-ISO15502, it is also necessary that the refrigerator experiences at least one defrost cycle.

In 1-day energy consumption tests the average duty cycle $\delta$ has been evaluated according to the following equation:

$\delta=A V E R A G E\left(\frac{t_{O N}}{t_{O N}+t_{O F F}}\right)$

where $t_{\mathrm{ON}}$ and $t_{\mathrm{OFF}}$ are the time when the compressor has been working $(\mathrm{ON})$ and when the compressor has been kept off (OFF).

\section{RESULTS AND DISCUSSION}

Table 1 and Table 2 summarise the experimental results obtained during the 1-day tests. These Tables report for each refrigerant fluid: the charge, the average temperatures and pressure in key points of the plant, the compression ratio, the density at the compressor inlet, the latent heat of evaporation, the average electric power consumption during the ON phase of the compressor, the average duty cycle.

The Tables clearly show that the mean value of the evaporating temperature $\left(\mathrm{T}_{1}\right)$ of the mixture HFC134a/HFO1234yf is very similar to the one proper of HFC134a, whereas the other fluids show mean values slightly higher. Therefore, being the thermal transmittance of both fluids almost the same, they can exchange the same refrigerant power in the freezer.

Another important parameter which influences the stability of lubricants and the compressor component is the temperature at the compressor outlet $\left(\mathrm{T}_{4}\right)$. The above-reported Tables reveal that the temperature of both the mixtures and of pure HFO1234ze are always lower than that of both HFC134a and HFO1234yf. Therefore, a longer compression life can be expected.
Table 1. Comparison between pure fluids in $24 \mathrm{~h}$ tests

\begin{tabular}{cccc}
\hline Parameter & $\mathrm{R} 134 \mathrm{a}$ & $\mathrm{R} 1234 \mathrm{yf}$ & $\mathrm{R} 1234 \mathrm{ze}$ \\
\hline $\mathrm{m}[\mathrm{g}]$ & 101 & 115 & 136 \\
\hline $\mathrm{p}_{3}[\mathrm{bar}]$ & 0.9 & 1.0 & 0.7 \\
\hline $\mathrm{p}_{4}[\mathrm{bar}]$ & 8.9 & 9.8 & 6.9 \\
\hline $\mathrm{T}_{3}\left[{ }^{\circ} \mathrm{C}\right]$ & 27.1 & 28.2 & 24.4 \\
\hline $\mathrm{T}_{4}\left[{ }^{\circ} \mathrm{C}\right]$ & 44.8 & 36.9 & 28.0 \\
\hline $\mathrm{T}_{\mathrm{co}}\left[{ }^{\circ} \mathrm{C}\right]$ & 34.8 & 38.2 & 36.1 \\
\hline $\mathrm{T}_{5}\left[{ }^{\circ} \mathrm{C}\right]$ & 34.4 & 36.9 & 28.0 \\
\hline $\mathrm{T}_{1}\left[{ }^{\circ} \mathrm{C}\right]$ & -28.6 & -27.6 & -26.9 \\
\hline $\mathrm{T}_{2}\left[{ }^{\circ} \mathrm{C}\right]$ & -22.01 & -23.4 & -22.4 \\
\hline $\mathrm{P}_{\mathrm{el}}[\mathrm{W}]$ & 48.0 & 54.2 & 45.8 \\
\hline & 9.9 & 9.8 & 9.9 \\
\hline $\mathrm{asp}\left[\mathrm{kg} / \mathrm{m}^{3}\right]$ & 3.7 & 5.3 & 3.4 \\
\hline $\mathrm{h}_{\mathrm{ev}}[\mathrm{kJ} / \mathrm{kg}]$ & 178 & 142 & 170 \\
\hline & 0.64 & 0.54 & 0.62 \\
\hline
\end{tabular}

Table 2. Comparison between mixtures in $24 \mathrm{~h}$ tests

\begin{tabular}{ccc}
\hline Parameter & $\mathrm{R} 134 \mathrm{a} / \mathrm{R} 1234 \mathrm{yf}$ & $\mathrm{R} 134 \mathrm{a} / \mathrm{R} 1234 \mathrm{ze}$ \\
\hline $\mathrm{m}[\mathrm{g}]$ & 116 & 137 \\
\hline $\mathrm{p}_{3}[\mathrm{bar}]$ & 1.1 & 0.8 \\
\hline $\mathrm{p}_{4}[\mathrm{bar}]$ & 9.4 & 9.8 \\
\hline $\mathrm{T}_{3}\left[{ }^{\circ} \mathrm{C}\right]$ & 25.6 & 25.2 \\
\hline $\mathrm{T}_{4}\left[{ }^{\circ} \mathrm{C}\right]$ & 43.2 & 41.3 \\
\hline $\mathrm{T}_{\mathrm{co}}\left[{ }^{\circ} \mathrm{C}\right]$ & 35.1 & 35.1 \\
\hline $\mathrm{T}_{5}\left[{ }^{\circ} \mathrm{C}\right]$ & 34.7 & 39.6 \\
\hline $\mathrm{T}_{1}\left[{ }^{\circ} \mathrm{C}\right]$ & -28.5 & -25.9 \\
\hline $\mathrm{T}_{2}\left[{ }^{\circ} \mathrm{C}\right]$ & -23.8 & -23.8 \\
\hline $\mathrm{P}_{\mathrm{el}}[\mathrm{W}]$ & 51.8 & 47.6 \\
\hline & 8.6 & 9.0 \\
\hline $\mathrm{asp}\left[\mathrm{kg} / \mathrm{m}^{3}\right]$ & 4.9 & 3.6 \\
\hline $\mathrm{h}_{\mathrm{ev}}[\mathrm{kJ} / \mathrm{kg}]$ & 147 & 172 \\
\hline & 0.50 & 0.60 \\
\hline
\end{tabular}

The refrigerant mass flow rate in the plant can be evaluated according the following equation:

$\dot{m}_{r e f}=\rho_{a s p} \times \eta_{V o l} \times \dot{V}$

Therefore, the latter depends on the density of the refrigerant fluid at the compressor inlet and on the volumetric efficiency of the compressor. The volumetric efficiency can be expressed as:

$\eta_{v}=1-m^{\prime}\left(\beta^{\gamma}-1\right)$

where $\mathrm{m}^{\prime}$ is the clearance rate:

$m^{\prime}=\frac{V_{3}}{V_{1}-V_{3}}$

Tables 1 and 2 show that the lower compression ratio is that of HFC134a/HFO1234yf mixture. This leads to a higher value of the compressor volumetric efficiency (see equation 6). The mixture presents also a higher vapour density. This leads to a higher mass flow rate, according to equation (5).

The mean ON power of HFO1234ze is $-4.6 \%$ lower than that of HFC134a. Whereas for the refrigerant fluids based on HFC1234yf the latter is always greater than that of pure HFC134a. Looking at the thermodynamic properties reported in Table1, one can observe that the latent heat of evaporation of HFC134a is greater than that of its substitutes. Therefore, for the refrigerant fluids based on HFO1234yf, despite the 
greater mass flow rate, the effect of latent heat prevails.

One can observe that the ON time of both pure HFO1234yf and HFO1234yf/HFC134a are significantly lower than that of HFC134a (-16 and $-22 \%$, respectively). Therefore, despite the electric power of both the refrigerant fluids based on HFO1234yf is only slightly lower than that of HFC134a, there is a significant energy saving on the daily energy consumption.

Figure 2 reports the yearly (E1y) electric energy consumption for all the refrigerants and the energy saving respect to HFC134a. $E_{H 24}$ is recorded over a 24-hours test and E1y is the projection of annual consumptions, calculated as follows:

$$
E_{1 y}=E_{H 24} \times 365 \text { days }
$$

In the bottom of the Figure is also reported the percentage variation between each refrigerant fluid and HFC134a.

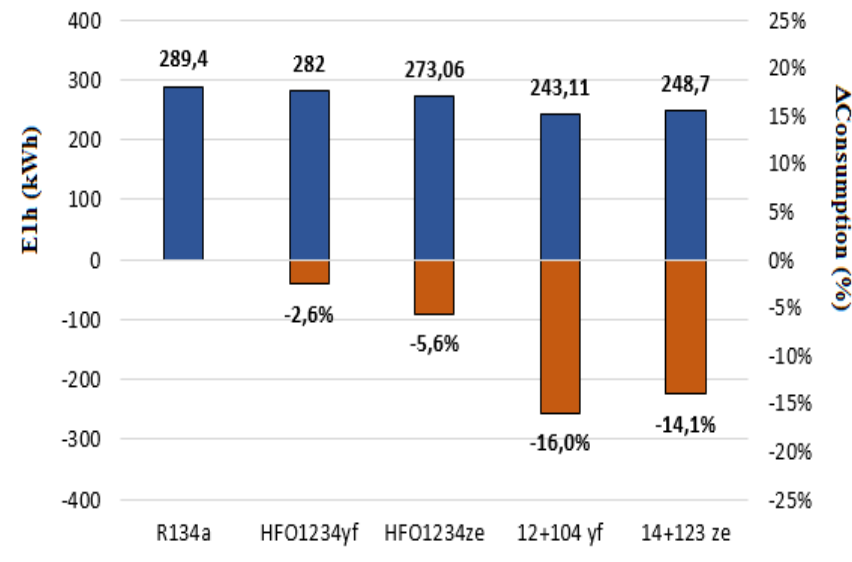

Figure 2. Yearly electric energy consumption and energy saving for the refrigerant fluids

It is evident that using both $\mathrm{HFO} / \mathrm{HFC}$ mixtures there is an energy saving respect to pure fluids. In particular, with HFO1234yf/HFC134a mixture the yearly energy saving is of $16 \%$.

In Figure 3 is reported the TEWI for all the refrigerant fluids.

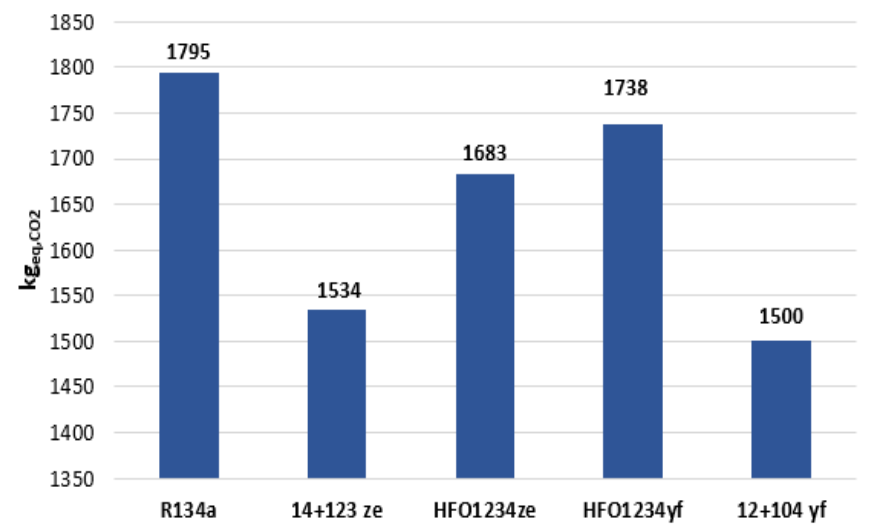

Figure 3. TEWI for the refrigerant fluids

It is evident that the use of all the HFO based refrigerant fluids leads to a reduction of the TEWI respect to HFC134a.

This is due to a reduction of both the direct and indirect contributions to global warming.

In Figure 4 is reported $\triangle \mathrm{TEWI}$ for all refrigerant fluids that are substitutes of HFC134a, evaluated as:

$\Delta T E W I=\frac{T E W I_{S F}-T E W I_{R 134 a}}{T E W I_{R 134 a}}$

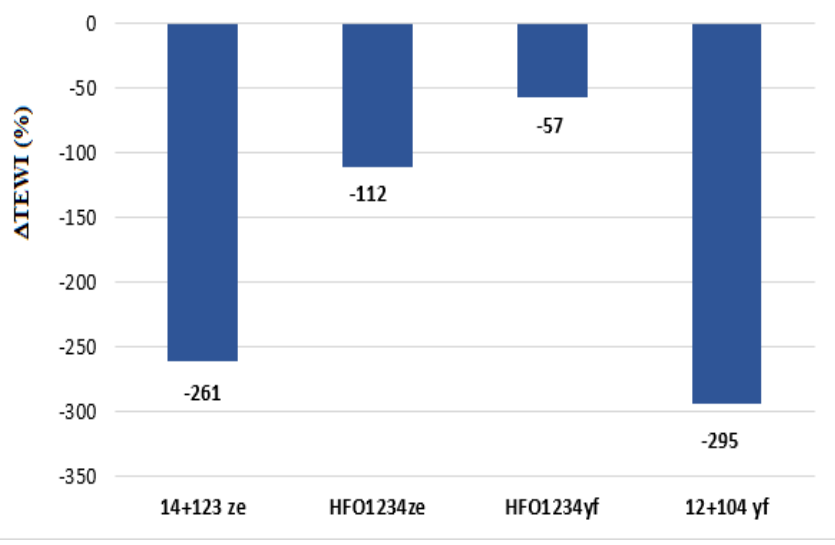

Figure 4. $\triangle \mathrm{TEWI}$ for the refrigerant fluids

The Figure clearly shows that the lower environmental impact in term of global warming can be achieved with both the mixtures. In particular, with HFC134a/HFO1234yf mixture there is reduction of the TEWI of- $295 \%$ respect to HFC134a.

\section{CONCLUSIONS}

The problem of substitution of HFC134a in terms of global warming effect has been examined, since according to the UE Regulation $N^{\circ} 517 / 2014$, HFCs with 150 or more as GWP has been forbidden from 1 January 2015 in domestic refrigerators.

HFC134a has a relevant direct global warming effect stemming from its absorption power of long-wave radiations, that depends on its GWP and on the fraction of refrigerant charge released in the atmosphere. Possible substitutes of HFC134a are the new generation of refrigerants HydroFluoroOlefins (HFOs). These refrigerants are characterized by low GWP and can be used pure (HFO1234yf and HFO1234ze) or mixed with HFC134a with a percentage not over $10 \%$ to guarantee a GWP lower than 150 .

In this paper a domestic refrigerator, that belongs to the A+ energetic class, has been instrumented in order to make an experimental comparison between HFC134a and HFO based refrigerant fluids. The comparison has been performed in terms of the total equivalent warming impacts (TEWI) that combine the effects of the direct emissions of refrigerants with the indirect effects of energy consumption.

Experimental tests have been performed in 1-day tests according to the normative UNI-EN-ISO15502.

The results obtained clearly show that the best refrigerant fluids are the mixtures. In particular, with the mixture HFC134a/HFO1234yf (10/90\% in weight) there is a reduction of the TEWI of $-295 \%$ respect to HFC134a. 


\section{REFERENCES}

[1] United Nation Environment Program (UN). (1987). Montreal Protocol on substances that deplete the ozone layer, New York (NY), USA.

[2] Mirandola A., Lorenzini E. (2016). Energy, environment and climate: From the past to the future, International Journal of Heat and Technology, Vol. 34, No. 2, pp. 159164. DOI: $10.18280 /$ ijht.340201

[3] United Nation Environment Program (UN). (1997). Kyoto Protocol to the United Nation Framework Convention on climate change., Kyoto, JPN.

[4] Aprea C., Greco A., Maiorino A. (2013). The substitution of R134a with R744: An exergetic analysis based on experimental data, International Journal of Refrigeration, Vol. 36, No. 8, pp. 2148-2159. DOI: 10.1016/j.ijrefrig.2013.06.012

[5] Aprea C., Greco A., Maiorino A. (2015). The application of a desiccant wheel to increase the energetic performances of a transcritical cycle, Energy Conversion and Management, Vol. 89, pp. 222-230. DOI: 10.1016/j.enconman.2014.09.066

[6] Aprea C., Greco A., Maiorino A., Masselli C. (2017). A comparison between electrocaloric and magnetocaloric materials for solid state refrigeration, International Journal of Heat and Technology, Vol. 35, No. 1, pp. 225-234. DOI: $\underline{10.18280 / \mathrm{ijht} .350130}$

[7] International Organization for Standardization. (2005). ISO 15502 Household refrigerating appliances Characteristics and test methods.

[8] Aprea C., Greco A., Maiorino A. (2012). An experimental evaluation of the greenhouse effect in the substitution of R134a with $\mathrm{CO}_{2}$, Energy, Vol. 45, pp.753-761. DOI: 10.1016/j.energy.2012.07.015

[9] Aprea C., Greco A. (1998). An experimental evaluation of the greenhouse effect in R22 substitution, Energy Conversion \& Management, Vol. 39, No. 9, pp. 877-887. DOI: $10.1016 / \mathrm{S} 0196-8904(97) 10058-9$

[10] Aprea C., Maiorino A. (2011). An experimental investigation of the global environmental impact of the R22 retrofit with R422D, Energy, Vol. 36, No. 2, pp. 1161-1170. DOI: $10.1016 /$ j.energy.2010.11.032

[11] Sand J.R., Fisher S.K., Baxter V.D. (1999). TEWI analysis: Its utility, its shortcomings, and its results, Proceedings of the Taipei International Conference on Atmospheric Protection, Taipei.

[12] Watson R.T., Albritton D.L. (2001). Third Assessment Report of The Intergovernmental Panel on Climate Change, Cambridge, United Kingdom.

[13] British Refrigeration Association. (2006). Guideline method of calculating TEWI, United Kingdom.

[14] Aprea C., Greco A., Maiorino A., Masselli C., Metallo A. (2016). HFO1234yf as a drop-in replacement for R134a in domestic refrigerators: a life cycle climate performance analysis, International Journal of Heat and Technology, Vol. 34, No. Sp. 2, pp. S212-S218. DOI: 10.18280/ijht.34S2

[15] Aprea C., Greco A., Maiorino A., Masselli C., Metallo A. (2016). HFO1234ze as drop-in replacement for R134a in domestic refrigerators: an environmental impact analysis, Energy Procedia, Vol. 101, pp. 964-971. DOI: 10.1016/j.egypro.2016.11.122

[16] Aprea C., Greco A., Maiorino A., Masselli C. (2015). Magnetic refrigeration: an eco-friendly technology for the

refrigeration at room temperature, Journal of Physics: Conference Series, Vol. 655, No. 1, p. 012026. DOI: $\underline{10.1088 / 1742-6596 / 655 / 1 / 012026}$

[17] Aprea C., Greco A., Maiorino A., Masselli C. (2017). Electrocaloric refrigeration: an innovative, emerging, ecofriendly refrigeration technique, IOP Conf. Series: Journal of Physics: Conf. Series, Vol. 796, p. 012019. DOI: 10.1088/1742-6596/796/1/012019

[18] Greco A., Mastrullo R., Palombo A. (1997). R407C as an alternative to R22 in vapour compression plant: An experimental study, International Journal of Refrigeration, Vol.21, No. 12, pp. 1087-1098. DOI: 10.1002/(SICI)1099114X(19971010)21:12<1087::AID-ER330>3.0.CO;2-Y

[19] Aprea C., Greco A., Maiorino A. (2017). An experimental investigation of the energetic performances of HFO1234yf and its binary mixtures with HFC134a in a household refrigerator, International Journal of Refrigeration, Vol. 76, pp. 109-117. DOI: $10.1016 /$ j.ijrefrig.2017.02.005

[20] Moffat R.J. (1988). Describing the uncertainties in experimental results, Exp. Therm. Fluid Sci., Vol. 1, pp. 3-17. DOI: 10.1016/0894-1777(88)90043-X

\section{NOMENCLATURE}

$\mathrm{C}$

$\mathrm{CO}_{2}$

$\mathrm{COP}$

$\mathrm{E}$

GWP

ODP

1

$\mathrm{m}$

m'

$\mathrm{p}$

$P$

$\mathrm{r}$

REC

$\mathrm{T}$

$\mathrm{t}$

TEWI

$\mathrm{V}$

V'

$\dot{V}$

\section{Greek symbols}

$\alpha$

$\beta$

$\gamma$

$\delta$

$\Delta \mathrm{h}$

$\eta$

$\rho$

\section{Subscripts}

$1 y$

$24 \mathrm{~h}$

asp

dir specific heat, $\mathrm{kJ} \mathrm{kg}^{-1} \cdot \mathrm{K}^{-1}$

contribution to global warming, $\mathrm{kg}_{\mathrm{CO} 2}$

Coefficient Of Performance

Electric energy consumption, kWh

Global Warming Potential

Ozone Depletion Potential

accidental refrigerant leaks per year, \% refrigerant charge. year ${ }^{-1}$

refrigerant charge, $\mathrm{kg}$

clearance rate

pressure, bar

power, $\mathrm{W}$

$\mathrm{CO}_{2}$ emission from power conversion, $\mathrm{kg}_{\mathrm{CO} 2}$. $\mathrm{kWhe}^{-1}$

refrigerant recycling rate, $\%$

temperature, ${ }^{\circ} \mathrm{C}$

time, $s$

Total Equivalent Warming Impact, $\mathrm{kg}_{\mathrm{CO} 2}$ volume, $\mathrm{m}^{3}$

plant useful life, years

volumetric flow rate, $\mathrm{m}^{3} . \mathrm{s}^{-1}$

$\mathrm{CO}_{2}$ emission from power conversion, $\mathrm{kg}_{\mathrm{CO} 2} \cdot \mathrm{kWhyr}^{-1}$

compression ratio

$\mathrm{Cp} / \mathrm{Cv}$

duty cycle

latent heat, $\mathrm{kJ}^{\mathrm{kg}} \mathrm{kg}^{-1}$

efficiency

density, kg. $\mathrm{m}^{-3}$

one year

one day

direct 


$\begin{array}{llll}\text { el } & \text { electric } & \text { ref } & \text { refrigerant } \\ \text { ev } & \text { evaporation } & \text { R134a } & \text { R134a } \\ \text { indir } & \text { indirect } & \text { SF } & \text { substitute fluid } \\ \text { ON } & \text { compressor on } & \text { v } & \text { constant volume } \\ \text { OFF } & \text { compressor off } & \text { vol } & \text { volumetric }\end{array}$

